\title{
Analisis Sistem Agribisnis Padi Sawah di Kawasan Ekowisata \\ (Studi Kasus Subak Sembung, Desa Peguyangan, Kecamatan Denpasar Utara)
}

\section{LISTIANA DEWI, DWI PUTRA DARMAWAN, I KETUT SUAMBA}

\author{
Program Studi Agribisnis, Fakultas Pertanian, Universitas Udayana \\ J1. PB. Sudirman Denpasar 80323 \\ Email: dekentib@gmail.com \\ dwiputradarmawan@yahoo.com
}

\begin{abstract}
Analysis of Wetland Rice Agribusiness System in Ecotourism Area (A Case Study of Subak Sembung, Peguyangan Village, District of North Denpasar)
\end{abstract}

The existence of subak land conversion in Denpasar City causes Denpasar Mayor to issue a policy to protect rice fields through development of Green Open Zone, especially rice fields for ecotourism purposes. Subak Sembung is a subak that becomes ecotourism area in the middle of the town. It is necessary to do research to analyze the system of wetland rice agribusiness in an ecotourism area. The purpose of this study was to determine the system of wetland rice agribusiness, profits and feasibility of rice field farming, as well as obstacles in the development of rice farming in Subak Sembung. The method used was qualitative descriptive analysis and quantitative descriptive analysis in the form of cost analysis, income, as well as analysis of revenue and cost balance. The results showed that upstream agro-industry subsystem, farming system, downstream agroindutrial subsystem, and supporting institution subsystem had a good relation. There is a special support institution (Subak Sembung ecotourism manager) that provides additional ecological and economic value through the sharing of the results of ecotourism management. The farmers did not receive a direct share of the management of ecotourism, but the farms earned a profit of Rp. 6,996,784.20 / ha, as well as the revenue and expense of 2.88. Obstacles faced by farmers were in the form of labor shortage of rice field tractor and pest insulation aphis. The conclusion of the research is the system of wetland rice agribusiness in Subak Sembung has been running quite well, rice farming is able to gain profits and said feasible to run in the future, and farmers experience barriers in the management of the farm.

Keywords: agribusiness system, rice paddy, ecotourism

\section{Pendahuluan}

\subsection{Latar Belakang}

Pertanian merupakan sektor penyedia bahan pangan berupa tanaman padi yang berfungsi menghasilkan beras untuk konsumsi masyarakat Indonesia. Pemenuhan 
produksi beras untuk masyarakat tentunya diperlukan prasarana guna menunjang kegiatan usahatani padi sawah yaitu jaringan irigasi. Lembaga pengelola air irigasi pada wilayah Propinsi Bali dikenal dengan istilah Subak (Sutawan, 2000, dalam Pitana, 2004). Subak merupakan suatu masyarakat hukum adat yang memiliki karakteristik sosio-agraris-religius, yang merupakan perkumpulan petani dalam mengelola air irigasi di lahan sawah (Windia, 2006). Berdasarkan data jumlah subak per kabupaten/kota di Propinsi Bali tahun 2015, diketahui Kota Denpasar merupakan wilayah yang memiliki jumlah subak paling rendah. Rendahnya jumlah subak tersebut disebabkan karena petani mengalih fungsikan lahan mereka. Melihat hal tersebut, Wali Kota Denpasar suatu Peraturan Daerah Kota Denpasar nomor 27 tahun 2011 tentang tata ruang wilayah kota Denpasar tahun 2011-2031 untuk melindungi lahan sawah pada pasal 42 ayat 6 mengenai pengembangan Ruang Terbuka Hijau (RTH) persawahan ekowisata.

Menurut Australian Department of Tourism (1999, dalam Fandeli, 2000) ekowisata merupakan perjalanan wisata bertanggung jawab terhadap kelestarian lingkungan dan kesejahteraan masyarakat setempat. Peran aktif dalam mengelola ekowisata ini penting karena potensi alam dan budaya memiliki nilai jual sebagai daya tarik ekowisata. Berbicara mengenai ekowisata, Subak Sembung merupakan salah satu subak yang telah menjadi kawasan ekowisata di tengah-tengah kota Denpasar. Kawasan ekowisata yang dibentuk menjadikan kegiatan usahatani pada Subak Sembung memiliki nilai jual sebagai objek wisata. Adanya hal tersebut, tentunya sistem agribisnis padi sawah Subak Sembung harus mampu berjalan dengan baik guna mendukung pengembangan kawasan ekowisata, sehingga perlu dilakukan penelitian untuk mengetahui sistem agribisnis padi sawah di kawasan ekowisata.

\subsection{Tujuan Penelitian}

Adapun tujuan dari penelitian ini adalah untuk (1) menganalisis sistem agribisnis padi sawah di Subak Sembung (2) menganalisis keuntungan dan kelayakan usahatani padi sawah di Subak Sembung, serta (3) mengetahui hambatan yang terjadi dalam pengembangan usahatani padi sawah di Subak Sembung.

\section{Bahan dan Metode}

\subsection{Lokasi dan Waktu Penelitian}

Penelitian dilaksanakan di Subak Sembung, Desa Peguyangan, Kecamatan Denpasar Utara, Kota Denpasar pada bulan Desember 2016 sampai Januari 2017. Pemilihan lokasi ditentukan secara sengaja (purposive) dengan pertimbangan Subak Sembung telah menjadi kawasan ekowisata di tengah-tengah kota.

\subsection{Populasi dan Sampel}

Populasi yang digunakan dalam penelitian yaitu seluruh anggota petani Subak Sembung yang berjumlah 192 petani. Menurut Sugiyono (2015), bila populasi 
diketahu jumlahnya, perhitungan sampel dapat menggunakan rumus persaman Slovin sebagai berikut.

$$
\mathrm{n}=\frac{\mathrm{N}}{1+\mathrm{N}(\mathrm{e})^{2}}
$$

Keterangan :

$\mathrm{n} \quad=$ Jumlah sampel

$\mathrm{N}=$ Jumlah populasi

e $\quad=$ Batas toleransi kesalahan $(10 \%)$

Adapun jumlah sampel yang digunakan sebanyak 66 petani. Teknik pengambilan sampel pada penelitian ini menggunakan metode random sampling.

\subsection{Jenis dan Sumber Data}

Jenis data yang digunakan dalam penelitian ini terdiri dari data kualitatif dan kuantitatif. Data kualitatif meliputi gambaran umum Subak Sembung, sistem agribisnis padi sawah, serta hambatan dalam pengembangan usahatani padi sawah di Subak Sembung. Data kuantitatif meliputi karakteristik responden, jumlah input produksi usahatani, harga input produksi usahatani, dan hasil produksi padi sawah. Sumber data penelitian ini meliputi data primer dan data sekunder. Data primer bersumber dari Pekaseh Subak Sembung, petani padi sawah di Subak Sembung, Ketua Gapoktan Mekar Sari Subak Sembung, Dinas Pertanian Tanaman Pangan dan Hortikultura Kota Denpasar, serta Ketua pengelola ekowisata Subak Sembung. Data sekunder berasal dari Dinas Kebudayaan Propinsi Bali, BPS Propinsi Bali, dan Kantor Desa Peguyangan Kecamatan Denpasar Utara.

\subsection{Teknik Pengumpulan Data}

Teknik pengumpulan data penelitian ini dilakukan dengan dua cara antara lain (1) wawancara, yaitu komunikasi dua arah secara langsung antara peneliti dengan responden dengan menggunakan kuisioner dan daftar pertanyaan dan (2) studi dokumentasi, yaitu teknik pengumpulan data dengan cara mengumpulkan data melalui jurnal, buku-buku, dan artikel terkait penelitian ini.

\subsection{Informan Kunci}

Teknik pengambilan informan kunci dilakukan secara purposive (sengaja). Pihak informan kunci dalam penelitian ini antara lain Pekaseh Subak Sembung, Ketua Gapoktan Mekar Sari Subak Sembung, Ketua pengelola ekowisata Subak Sembung, serta Dinas Pertanian Tanaman Pangan dan Hortikultura Kota Denpasar.

\subsection{Metode Analisis Data}

\subsubsection{Analisis sistem agribisnis padi sawah}

Tujuan satu untuk menganalisis sistem agribisnis padi sawah di Subak Sembung dilakukan secara deskriptif kualitatif guna mengetahui subsistem 
agroindustri hulu, subsistem usahatani, subsistem agroindustri hilir, serta subsistem lembaga penujang.

\subsubsection{Analisis tingkat keuntungan dan kelayakan usahatani padi sawah}

Tujuan dua untuk menganalisis keuntungan dan kelayakan usahatani padi sawah di Subak Sembung, dianalisis secara deskriptif kuantitatif melalui perhitungan analisis biaya dan pendapatan usahatani serta analisis $\mathrm{R} / \mathrm{C}$ rasio.

1. Analisis biaya dan pendapatan usahatani

a. Biaya tenaga kerja

Menurut Suratiyah (2008), biaya tenaga kerja merupakan hasil perkalian Hari Orang Kerja (HOK) dengan upah tenaga kerja. Berikut rumus HOK tersebut.

$$
\mathrm{HOK}=\frac{\text { (jumlah hari kerja } \mathrm{x} \text { jumlah tenaga kerja } \mathrm{xjam} \text { kerja) }}{8 \text { jam }}
$$

b. Biaya penyusutan

Menurut Suratiyah (2015), biaya penyusutan dapat diketahui dengan menggunakan metode garis lurus (straight-line method). Berikut adalah rumus biaya penyusutan tersebut.

$$
\text { Biaya penyusutan }=\frac{\text { nilai beli-nilai sĩsa }}{\text { usia elkonomis (tahun) }} \text {. }
$$

c. Total biaya

Menurut Kasim (2004) total biaya usahatani merupakan penjumlahan dari seluruh biaya tunai dengan biaya yang diperhitungkan dalam menjalankan usahatani. Berikut adalah rumus mencari total biaya.

$$
\mathrm{TC}=\mathrm{TC}_{\mathrm{e}}+\mathrm{TC}_{\mathrm{i}}
$$

Dimana:

TC = Total biaya usahatani $(\mathrm{Rp})$

$\mathrm{TC}_{\mathrm{e}} \quad=$ Total biaya eksplisit atau tunai $(\mathrm{Rp})$

$\mathrm{TC}_{\mathrm{i}}=$ Total biaya implisit atau diperhitungkan ( $\left.\mathrm{Rp}\right)$

d. Penerimaan

Total penerimaan dihitung dengan mengalikan jumlah produksi dengan harga pasar (Soekartawi, 1986). Berikut adalah rumus menghitung penerimaan.

$$
\mathrm{TR}=\mathrm{P} \times \mathrm{Q} \text {. }
$$

Dimana:

$\mathrm{TR}=$ Total penerimaan $(\mathrm{Rp})$

$\mathrm{P} \quad=$ Harga jual produksi dalam usahatani (Rp/are)

$\mathrm{Q} \quad=$ Jumlah produksi dalam usahatani $(\mathrm{Rp})$

e. Pendapatan

Menurut Kasim (2004) pendapatan atas biaya total disebut dengan keuntungan. Berikut rumus menghitung pendapatan atas biaya total. 


$$
\pi=\mathrm{TR}-\mathrm{TC}
$$

Dimana:

$\pi \quad=$ Keuntungan $(\mathrm{Rp})$

$\mathrm{TR}=$ Total penerimaan $(\mathrm{Rp})$

$\mathrm{TC}=$ Total biaya usahatani $(\mathrm{Rp})$

2. Analisis imbangan penerimaan dan biaya ( $\mathrm{R} / \mathrm{C}$ rasio)

Menurut Kasim (2004) analisis R/C rasio merupakan perbandingan antara penerimaan dengan biaya yang dikeluarkan dalam usahatani. Berikut adalah rumus analisis tersebut.

$$
\text { R/C Biaya Total }=\frac{T R}{T C}
$$

Keterangan:

$\mathrm{TR}=$ Total penerimaan $(\mathrm{Rp})$

$\mathrm{TC}=$ Total biaya $(\mathrm{Rp})$

Adapun kriteria dari analisis ini antara lain (1) R/C > 1 dikatakan layak, (2) $\mathrm{R} / \mathrm{C}<1$ dikatakan tidak layak, dan $(3) \mathrm{R} / \mathrm{C}=1$ dikatakan impas.

\subsubsection{Analisis hambatan usahatani padi sawah}

Tujuan tiga ini dianalisis secara deskriptif kualitatif untuk mengetahui faktorfaktor yang menjadi penghambat seperti kendala non teknis dan kendala dalam pengelolaan usahatani padi sawah tersebut.

\section{Hasil dan Pembahasan}

\subsection{Analisis Sistem Agribisnis Padi Sawah di Subak Sembung, Desa Peguyangan, Kecamatan Denpasar Utara}

\subsubsection{Analisis subsistem agroindustri hulu}

Subsistem agroindustri hulu merupakan kegiatan yang meliputi pengadaan sarana produksi bagi pertanian. Menurut responden petani untuk mendapatkan sarana produksi dalam usahataninya cukup mudah. Pengadaan sarana benih diperoleh melalui penyusunan Daftar Usulan Pembelian Benih Bersubsidi yang bertujuan untuk menekan biaya produksi melalui subsidi dari Dinas Pertanian Tanaman Pangan dan Hortikultura Kota Denpasar. Terdapat dua jenis bantuan benih yang diberikan yaitu benih bersubsidi berupa varietas ciherang dan secara gratis berupa varietas situ bagendit. Bantuan benih tersebut diletakkan pada kios yang dikelola oleh Gapoktan Mekar Sari Subak Sembung. Pengadaan pupuk menurut responden dikatakan cukup mudah dan diperoleh melalui penyusunan Rencana Definitif Kebutuhan Kelompok yang bertujuan untuk memperoleh bantuan pupuk bersubsidi dari Dinas Pertanian Tanaman Pangan dan Hortikultura Kota Denpasar. Bantuan subsidi pupuk yang diperoleh yaitu pupuk Urea. Bantuan subsidi pupuk tersebut diletakkan pada kios Gapoktan Mekar Sari Subak Sembung. Petani padi sawah di Subak Sembung dalam kegiatan usahatani juga menggunakan pupuk NPK Phonska. 
Pengadaan pestisida diperoleh petani berasal dari kios UD. Botani dan kios Gapoktan Mekar Sari Subak Sembung. Menurut responden petani pengadaannya cukup mudah akibat tempat pembeliannya mudah dijangkau. Terdapat dua jenis pestisida yang digunakan petani yaitu herbisida meliputi DMA dan ally plus, sedangkan insektisida meliputi confidor dan fastac. Sumber pengadaannya berasal dari kios UD. Botani dan kios Gapoktan Mekar Sari Subak Sembung. Pengadaan tenaga kerja menurut responden cukup tersedia. Tenaga kerja yang digunakan dalam usahatani padi sawah di Subak Sembung terdiri TKDK dan TKLK. TKDK biasanya berasal dari petani pemilik usahatani beserta istri, anak, maupun keluarganya, sedangkan pengadaan TKLK sebagian besar berasal dari penduduk di luar Kota Denpasar. Pengadaan sarana produksi alat-alat pertanian terbilang cukup mudah karena banyak tersedia pada pasar dan kios-kios pertanian. Alat-alat pertanian yang digunakan oleh petani tersebut antara lain sprayer, cangkul, sabit, dan mesin rabas.

\subsubsection{Analisis subsistem usahatani}

Usahatani padi sawah yang dilakukan oleh petani Subak Sembung terbilang cukup lancar yang dimulai dari persemaian, pengolahan lahan, penanaman, pemupukan, pemeliharaan tanaman, serta pemanenan. Hal ini disebabkan karena sarana produksi usahatani padi sawah mampu tersedia dengan baik. Kegiatan ini diarahkan oleh Dinas Pertanian Tanaman Pangan dan Hortikultura Kota Denpasar untuk menghasilkan pangan tanpa bahan kimia dengan tujuan untuk mencapai hasil produksi bersifat organik, namun kenyataannya budidaya padi sawah di Subak Sembung belum sepenuhnya bersifat organik akibat masih terdapat residu kimia dalam tanah sisa akibat penerapan usahatani sebelumnya.

\subsubsection{Analisis subsistem agroindustri hilir}

Berdasarkan responden petani di Subak Sembung, mereka tidak melakukan pengolahan pasca panen pada tanaman padinya. Hal ini dikarenakan petani sudah menjual tanaman padi dengan sistem tebasan. Kegiatan pemasaran hanya dilakukan sampai pada penebas saja yang diawali dengan penebas datang ke lahan untuk melakukan survei, kemudian menentukan harga sesuai keadaan tanaman padi. Pembayaran dilakukan secara tunai oleh penebas setelah gabah dipanen.

\subsubsection{Analisis subsistem lembaga penunjang umum}

Terdapat dua pihak yang menjadi lembaga penunjang dalam usahatani padi sawah di Subak Sembung diantaranya, (1) Dinas Pertanian Tanaman Pangan dan Hortikultura Kota Denpasar yang berperan dalam memberikan bantuan subsidi sarana produksi benih dan pupuk dan (2) Gapoktan Mekar Sari Subak Sembung yang berperan sebagai tempat penyediaan bantuan subsidi sarana produksi padi, dan memberikan pinjaman dana untuk pembayaran awal ketika bantuan subsidi sarana produksi benih dan pupuk tiba untuk petani di Subak Sembung. 


\subsubsection{Analisis subsistem lembaga penunjang khusus}

Terdapat lembaga penunjang khusus berupa pengelola ekowisata yang dibentuk oleh Subak Sembung sejak tahun 2014. Lembaga ini dikatakan bersifat khusus karena memiliki keterkaitan atau bersifat saling mendukung dalam pengembangan ekowisata. Usahatani pada Subak Sembung digunakan sebagai objek wisata bagi para pengunjung dalam pengembangan ekowisata tersebut. Adanya pengembangan kawasan tersebut menyebabkan Subak Sembung memperoleh manfaat seperti adanya konservasi lahan usahatani, pembaharuan infrastruktur jalan usahatani yang dapat membantu petani dalam membawa sarana produksi usahatani, serta adanya tambahan nilai ekonomis berupa penerimaan 10 persen bagi Subak Sembung yang seluruhnya dimasukkan ke dalam kas subak dan diakumulasikan sebagai biaya upacara Subak Sembung. Hal ini menunjukkan bahwa petani di Subak Sembung belum mampu merasakan hasil dari pengelolaan ekowisata secara langsung. Selain itu, terjadi peningkatan harga produksi yang mampu ditawarkan petani kepada tengkulak. Hal ini diakibatkan oleh adanya kemudahan akses tengkulak dalam membawa hasil panen dari lahan sawah milik petani.

Peranan dari lembaga ini adalah mengatur jalannya program ekowisata seperti berkoordinasi terkait paket-paket wisata yang diminati oleh pengunjung hingga menentukan pihak yang terlibat seperti anggota petani dalam pelaksanaan paket kunjungan belajar Subak dalam kegiatan pengolahan lahan dan menanam padi atau nandur. Lembaga ini juga berperan dalam menjalin kerjasama dengan instansi terkait serta berperan membagi kontribusi dari hasil pengelolaan ekowisata kepada pihakpihak yang terlibat termasuk anggota petani di Subak Sembung.

\subsection{Analisis Keuntungan dan Kelayakan Usahatani Padi Sawah di Subak Sembung, Desa Peguyangan, Kecamatan Denpasar Utara}

Terkait pengembangan ekowisata Subak Sembung, diketahui bahwa petani belum mampu merasakan penerimaan secara langsung dari pengelolaan ekowisata. Penerimaan usahatani padi sawah di Subak Sembung dihitung dari penjualan padi sawah pada musim tanam bulan Juli-Oktober 2016 dengan sistem tebasan. Biaya yang dikeluarkan petani terdiri atas dua komponen yaitu biaya tunai dan biaya yang diperhitungkan. Biaya tunai terdiri dari biaya tetap dan biaya variabel. Biaya tetap meliputi iuran subak (pengoot), biaya variabel meliputi biaya benih, biaya pupuk, biaya obat-obatan, serta biaya TKLK untuk kegiatan pengolahan lahan serta penanaman bibit padi sawah. Biaya yang diperhitungkan meliputi biaya tetap seperti penyusutan alat-alat pertanian, biaya variabel meliputi biaya TKDK dan biaya upakara dalam kegiatan usahatani padi sawah selama satu musim tanam. Analisis biaya dan pendapatan usahatani padi sawah di Subak Sembung tidak dibedakan atas dasar kepemilikan lahan karena dihitung hanya untuk mengetahui keuntungan keseluruhan dari usahatani padi sawah di Subak Sembung. Hasil analisis rata-rata biaya dan pendapatan petani padi sawah Subak Sembung dapat dilihat pada tabel 1. 
Tabel 1.

Rata-Rata Biaya dan Pendapatan Usahatani Padi Sawah Subak Sembung per Hektar per Musim Tanam Juli-Oktober 2016

\begin{tabular}{|c|c|c|c|}
\hline Ket & Komponen biaya & Nilai (Rp/ha) & Persentase (\%) \\
\hline A. & Total penerimaan & $10.711 .363,64$ & - \\
\hline \multicolumn{4}{|c|}{ Biaya tunai } \\
\hline \multirow[t]{11}{*}{ B. } & Biaya tetap & & \\
\hline & a. Iuran subak & $76.909,09$ & 2,07 \\
\hline & Sub total & $76.909,09$ & 2,07 \\
\hline & $\underline{B i a y a}$ variabel & & \\
\hline & a. Benih & 29.272 .73 & 0,79 \\
\hline & b. Pupuk & $468.492,42$ & 12,61 \\
\hline & c. Obat-obatan & $86.130,30$ & 2,32 \\
\hline & d. TKLK & $1.556 .393,94$ & 41,90 \\
\hline & Sub total & $2.140 .289,39$ & 57,62 \\
\hline & Total biaya tunai & $2.217 .198,48$ & 59,69 \\
\hline & Biaya c & rhitungkan & \\
\hline \multirow[t]{8}{*}{ C. } & Biaya tetap & & \\
\hline & a. Penyusutan alat-alat pertanian & $80.638,53$ & 2,17 \\
\hline & Sub total & $80.638,53$ & 2,17 \\
\hline & $\underline{B i a y a}$ variabel & & \\
\hline & a. TKDK & 1.006.060,61 & 27,08 \\
\hline & b. Upakara & $410.681,82$ & 11,06 \\
\hline & Sub total & $1.416 .742,42$ & 38,14 \\
\hline & Total biaya diperhitungkan & $1.497 .380,95$ & 40,31 \\
\hline D. & Total biaya $(\mathrm{B}+\mathrm{C})$ & $3.714 .597,44$ & 100,00 \\
\hline E. & Pendapatan atas biaya total (A-D) & $6.996 .784,20$ & - \\
\hline
\end{tabular}

Sumber : data primer (diolah), 2017

Berdasarkan data pada tabel 1, biaya yang paling besar dikeluarkan oleh petani adalah total biaya tunai dibandingkan dengan total biaya yang diperhitungkan, hal ini dikarenakan sebagian besar petani mengalokasikan untuk biaya TKLK dalam kegiatan penanaman padi dan membajak lahan sawah yakni sebesar Rp 1.556.393,94 $\mathrm{HOK} /$ ha atau persentase sebesar $41,90 \%$ dengan menggunakan sistem borongan. Biaya tersebut juga dialokasikan untuk pembelian pupuk sebesar Rp 468.492,42/ha atau sebesar $12,61 \%$ dari total biaya usahatani. Besarnya biaya sarana pupuk disebabkan padi memerlukan banyak unsur hara guna menunjang pertumbuhannya. Biaya yang diperhitungkan pada usahatani padi sawah di Subak Sembung di dominasi oleh rata-rata biaya TKDK sebesar Rp 1.006.060,61 HOK/ha dengan persentase $27,08 \%$ dari total biaya usahatani. Besarnya biaya ini disebabkan tanaman padi sawah sangat rentan terhadap hama dan penyakit sehingga membutuhkan perawatan yang cukup intensif dalam pemeliharaannya. Besarnya total biaya usahatani yang dikeluarkan petani pada musim tanam Juli-Oktober 2016 adalah ratarata sebesar Rp 3.714.597,44/ha dan total penerimaan produksi padi diperoleh ratarata sebesar Rp 10.711.363,64/ha, sehingga diketahui pendapatan atas total biaya 
yang merupakan keuntungan diperoleh rata-rata sebesar Rp 6.996.784,20/ha. Tingginya pendapatan atas total biaya yang diterima karena petani mendapat bantuan subsidi benih dan pupuk serta tidak dibebankan biaya pajak akibat menjadi kawasan hijau, sehingga responden petani mampu memperoleh keuntungan dari kegiatan usahatani padi sawah di Subak Sembung.

Tingkat kelayakan usahatani padi sawah di Subak Sembung dapat diketahui dengan menggunakan analisis $\mathrm{R} / \mathrm{C}$ rasio yaitu perbandingan antara penerimaan dengan biaya. Analisis dari R/C rasio dapat dilihat pada tabel 2 berikut.

\section{Tabel 2.}

Analisis R/C Rasio Usahatani Padi Sawah Subak Sembung per Hektar pada Musim Tanam Juli-Oktober 2016

\begin{tabular}{llr}
\hline No & \multicolumn{1}{c}{ Uraian } & \multicolumn{1}{c}{ Jumlah (Rp/ha) } \\
\hline 1. & Penerimaan & $10.711 .363,64$ \\
2. & Biaya tunai & $2.217 .198,48$ \\
3. & Biaya yang diperhitungkan & $1.497 .380,95$ \\
4. & Total Biaya & $3.714 .597,44$ \\
5. & R/C rasio atas biaya total & 2,88 \\
\hline
\end{tabular}

Sumber: data primer (diolah), 2017

Perhitungan analisis $\mathrm{R} / \mathrm{C}$ rasio dalam penelitian ini hanya dilihat dari $\mathrm{R} / \mathrm{C}$ rasio atas biaya total dari usahatani tersebut. Diketahui $\mathrm{R} / \mathrm{C}$ ratio atas biaya total sebesar 2,88 yang artinya setiap satu rupiah biaya total yang dikeluarkan petani akan memperoleh penerimaan sebesar Rp 2,88. Maka, usahatani padi sawah di Subak Sembung dikatakan layak untuk dijalankan ke depannya.

\subsection{Hambatan Pengembangan Usahatani Padi Sawah di Subak Sembung, Desa Peguyangan, Kecamatan Denpasar Utara}

Menurut responden petani, hambatan yang dihadapi adalah berupa yaitu berupa kendala pengeloaan usahatani seperti kekurangan tenaga kerja untuk membajak sawah dengan mesin traktor dan gangguan hama wereng hijau yang menyebabkan pertumbuhan tanaman menjadi kerdil dan cenderung batang padi berwarna kuning.

\section{Simpulan dan Saran}

\subsection{Simpulan}

Sistem agribisnis padi sawah di kawasan ekowisata menunjukkan antara subsistem sudah berjalan cukup baik, namun masih perlu dilakukan perbaikan lebih lanjut. Terdapat sebuah lembaga penunjang khusus yang memiliki keterkaitan dengan usahatani di Subak Sembung dan berperan menambah nilai ekologis dan ekonomis bagi Subak tersebut. Kegiatan usahatani padi sawah di Subak Sembung mampu memperoleh keuntungan dan usahataninya dikatakan layak untuk dijalankan kedepannya. Hambatan yang dihadapi petani dalam usahatani padi sawah tersebut berupa kekurangan tenaga kerja traktor lahan dan gangguan hama wereng. 


\subsection{Saran}

Saran yang dapat diberikan dalam penelitian ini yaitu (1) pengelola ekowisata diharapkan melakukan kerja sama dengan pemerintah mengenai pelatihan manajemen ekowisata, (2) sebaiknya organisasi Subak Sembung membuat aturan mengenai pembagian hasil dari pengelolaan ekowisata, (3) Subak Sembung tidak hanya dijadikan sebagai objek melainkan sebagai subjek dalam pengelolaan kawasan Ekowisata, (4) sebaiknya petani membentuk koperasi agribisnis guna memutus pemasaran secara tebasan, (5) kekurangan tenaga kerja untuk traktor lahan diatasi dengan memfungsikan bantuan mesin traktor dari pemerintah, dan (6) pengendalian hama wereng sebaiknya petani melakukan penjarangan jarak tanam.

\section{Ucapan Terimakasih}

Ucapan terimakasih ini peneliti tujukan kepada seluruh pihak yang telah membantu dalam pelaksanaan penelitian hingga karya ilmiah ini bisa dipublikasikan dalam e-jurnal.

\section{Daftar Pustaka}

Dinas Kebudayaan Propinsi Bali. 2016. Data Bali Membangun 2016. Badan Perencanaan Pembangunan Daerah: Denpasar.

Fandeli, Chafid. 2000. Pengertian dan Konsep Ekowisata. Jurnal. Fakultas Kehutanan. Universitas Gadjah Mada: Yogyakarta. http://saveforest.webs.com/konsep_ekowisata.pdf. Diakses pada tanggal 21 November 2016

Kasim, S. 2004. Petunjuk Menghitung Keuntungan dan Pendapatan Usahatani. Universitas Lambung Mangkurat: Banjarbaru.

Pitana, Gde dan Setiawan AP., Gede. 2004. Revitalisasi Subak dalam Memasuki Era Globalisasi. Andi: Yogyakarta.

Sistem Informasi Pembangunan Daerah. 2011. Rencana Tata Ruang Wilayah Kota Denpasar. http://sipd.bangda.kemendagri.go.id/dokumen/uploads/rtrw_299_2016.pdf. Diakses pada tanggal 26 Desember 2016.

Soekartawi. 1986. Ilmu Usahatani dan Penelitian untuk Pengembangan Petani Kecil. Jakarta: UI Press.

Sugiyono. 2015. Metode Penelitian Tindakan Komprehensif (Untuk Perbaikan Kinerja dan Pengembangan Ilmu Tindakan). CV. Alfabeta: Yogyakarta.

Suratiyah, Ken. 2008. Ilmu Usahatani. Penebar Swadaya: Jakarta.

Suratiyah, Ken. 2015. Ilmu Usahatani Edisi Revisi. Penebar Swadaya: Jakarta.

Windia, Wayan. 2006. Transformasi Sistem Irigasi Subak yang Berlandaskan Konsep Tri Hita Karana. PT. Offset BP Denpasar: Jakarta. 